\title{
Metabolic costs of pursuit and attack in early larval Atlantic cod
}

\author{
Ione Hunt von Herbing ${ }^{1, *}$, Scott M. Gallager ${ }^{2}$, William Halteman ${ }^{3}$ \\ ${ }^{1}$ School of Marine Sciences, University of Maine, Orono, Maine 04469, USA \\ ${ }^{2}$ Woods Hole Oceanographic Institute, University of Maine, Orono, Maine 04469, USA \\ ${ }^{3}$ Department of Mathematics and Statistics, University of Maine, Orono, Maine 04469, USA
}

\begin{abstract}
Metabolic costs of pursuit and attack for early larval Atlantic cod (Gadus morhua) feeding on 2 different prey types, a protozoan (Balanion sp.) and a copepod nauplius (Pseudodiaptomis sp.) were estimated from 5 to $20 \mathrm{~d}$ post-hatch. Parameters describing feeding patterns were determined from 3-dimensional observations using 2 orthogonal cameras. Feeding parameters were calculated using a digital image-analysis system for larvae in 3 size classes, and included pursuit duration, distance and speed for both burst and glide components, and attack duration, distance and speed. Metabolic rates were estimated for each component of pursuit and attack from the relationship between specific metabolic rate and swimming speed from previous respirometry studies on cod larvae. Estimated specific metabolic rates were used in a new model to determine specific and total energy expenditures, which incorporated each of the components of pursuit and attack. Values of total energy expenditure were used in a model to determine relative net energy gain during pursuit and attack of a larva on a protozoan and a copepod nauplius in 3 larval size classes. In Size Class 1 (5 to $6 \mathrm{~mm}$ total length, TL) first-feeding larval cod were small and poorly developed, had long pursuit and attack times and distances, and slow swimming speeds. In Size Classes 2 (6 to $7 \mathrm{~mm}$ TL) and 3 ( 7 to $8 \mathrm{~mm}$ TL) larger larvae were better developed, had shorter pursuit and attack times and distances, and faster swimming speeds. Specific metabolic rates during pursuit of a protozoan increased with increasing larval size, while specific energy expenditure decreased due to shorter pursuit times. Results from net energy gain equations showed that a cod larva gained 3 orders of magnitude more energy from consumption of a nauplius than a protozoan even though its energy expenditure during pursuit of a nauplius was 2 to 3 times that during pursuit of a protozoan.
\end{abstract}

KEY WORDS: Atlantic cod larvae $\cdot$ Protozoan $\cdot$ Copepod nauplius $\cdot$ Prey capture $\cdot$ Feeding $\cdot$ Pursuit Energy expenditure $\cdot$ Net energy gain

Resale or republication not permitted without written consent of the publisher

\section{INTRODUCTION}

Most larval fishes are active planktonic predators that feed on motile prey. Almost all of the larval fish diet consists of a combination of prey types that range from ciliates to copepod nauplii which swim at different speeds and using different patterns. For example, small ciliated protozoans swim slowly in predictable patterns whereas nauplii swim with rapid unpredictable jumps (Buskey et al. 1993). Since all larval fishes are active

${ }^{*}$ E-mail: ivonherb@umenfa.maine.edu predators, swimming activity is the most important factor influencing energy expenditure, turnover and energy budgets (Ware 1975, Brett \& Groves 1979).

Shifts in larval fish diet have been documented in marine and freshwater species and are related to larval characteristics including morphology, metabolic constraints and swimming speed (Vlymen 1974, Hunter 1981, Kiørboe \& Visser 1999), and prey characteristics including size, morphology, abundance and vulnerability to predators (Buskey et al. 1993, Viitasalo et al. 1998). Studies of larval fish feeding-behavior (Browman \& O'Brien 1992a,b, Coughlin et al. 1992, Hunt von 
Herbing \& Gallager 2000) found that the frequency of prey capture increased with larval size because larger larvae swam faster and could capture a greater range of prey types and sizes. In addition, larger larvae could control their approach during pursuit, decelerating as they neared the prey and decreasing the probability of detection of the predator by the prey (Viitasalo et al. 1998, Kiørboe \& Visser 1999). In addition, increases in frequency of prey capture of larger prey were related to increases in the net rate of energy gain per unit time and served to meet size-related metabolic demands (O'Brien et al. 1989). Maximizing the net rate of energy gain through minimizing energy expenditure by selection of the most energetically profitable prey type would be likely to result in higher larval growth rates and decreased mortality, yet few studies have determined the energy expenditure and net energy gain of larval fishes feeding on different prey types. Estimates of the energy expenditures and energy gains associated with feeding are particularly important if we are to understand the ecology of a life stage for which growth and mortality rates are the highest in its life history. Such estimates will provide useful information for future studies on the energy budgets of larval fishes both in the field and in culture.

Recent laboratory and field studies in Atlantic cod (Gadus morhua) larvae found a shift in diet from a small protozoan (Balanion sp.) to a larger copepod nauplius (Pseudodiaptomus sp.) (Gallager et al. 1996, Hunt von Herbing \& Gallager 2000). In these studies, first-feeding larval Atlantic cod were able to feed on protozoans and could capture copepod nauplii at 8 to $9 \mathrm{~d}$ post-hatching. Older larvae (>10 d post-hatching) fed on a greater range of prey types and sizes that included both nauplii and protozoans (Gallager et al. 1996, Hunt von Herbing \& Gallager 2000). Protozoans are small (30 to $50 \mu \mathrm{m})$, and swim in predictable patterns (Buskey et al. 1993), and contain low total amounts of energy (Finlay \& Uhlig 1981, Putt \& Stoecker 1989), whereas copepod nauplii are larger (80 to $250 \mu \mathrm{m}$ ), swim faster, and provide an order of magnitude more energy than protozoans (Lasker 1962, Houde \& Schekter 1983). Hunt von Herbing \& Gallager (2000) found that first-feeding larval cod readily perceived and captured protozoans, but seemed less able to capture copepod nauplii because naupliar escape speeds were faster than larval maximal swimming speeds. In addition, early larval cod lack fine control over their swimming speeds and may be easily detectable to copepods, which have specialized antennae for detecting vibrations in the water column (Strickler \& Bal 1973, Strickler 1975). In this study, we estimated size-related changes in energy expenditure and net energy gain of larvae fed on 2 different planktonic prey, a protozoan and a copepod nauplius.

\section{MATERIALS AND METHODS}

Rearing cod larvae and prey. Fertilized Atlantic cod (Gadus morhua) eggs were obtained between December 1991 and July 1992 and between January and March 1994, from a Scotian Shelf population of fish located at the experimental aquaculture facility at Canadian Department of Fisheries and Oceans St. Andrews Biological Station, St. Andrews, New Brunswick, Canada. Fertilized eggs were transported in insulated coolers (at $2^{\circ} \mathrm{C}$ ) to culture facilities at the Environmental Systems Laboratory at Woods Hole Oceanographic Institution, Woods Hole, Massachusetts, USA, and to the Aquatron facilities at Dalhousie University, Halifax, Nova Scotia, Canada, where they were acclimated over a period of hours to $8.0 \pm 1^{\circ} \mathrm{C}$. Eggs were incubated at $8.0 \pm 1{ }^{\circ} \mathrm{C}$ in 201 black plastic incubation tanks held in a constant temperature room. Ten to $12 \mathrm{~d}$ after fertilization (hatching occurred over a $3 \mathrm{~d}$ period), larvae were moved to $100 \mathrm{l}$ static black rearing tanks where they were kept until the end of the experiments and could be fed liberally with cultured prey items to ensure good survival. Water was partially replaced every $3 \mathrm{~d}$ with $1 \mu \mathrm{m}$-filtered sea water and the prey were kept in suspension by gently bubbling air through the tanks. Larvae were fed to satiation at least 2 to 3 times per day, and they fed well in the rearing tanks. All larvae used in the experiments appeared in good condition prior to transfer to the observation tanks.

For feeding studies, prey items consisted of protozoans (Balanion sp., 30 to $50 \mu \mathrm{m}$ ) and copepod nauplii (Pseudodiaptomus sp., 100 $\mathrm{mm}$ ) which were cultured in high densities in the laboratory using the techniques of Stoecker et al. (1981). Protozoans and copepod nauplii were fed to larval fish in the rearing tanks throughout the experimental period. In addition, rotifers and wild zooplankton, sieved to appropriate sizes, were fed to the larvae throughout the experimental period. Prey density (as determined from counts of ten $1 \mathrm{ml}$ aliquots) was kept high (>20 prey $\mathrm{ml}^{-1}$ ) to ensure good feeding conditions for all larvae. High combined concentrations $\left(5 \times 10^{4}\right.$ cells ml $\left.{ }^{-1}\right)$ of algae (Isochrysis sp. and Heterocapsa triquetra) were added daily to each tank.

Feeding behavior - experimental design. Larval cod swimming duration, distance and speed during pursuit were estimated from 89 (61 successful and 28 unsuccessful) events of cod larvae feeding on protozoans and 20 (10 successful and 10 unsuccessful) events of cod larvae feeding on copepod nauplii. Sequences of pursuit and attack of cod larvae on protozoans and copepod nauplii were recorded from $5 \mathrm{~d}$ (first-feeding) to $20 \mathrm{~d}$ post-hatch. Observations took place daily until the larvae were $10 \mathrm{~d}$ post-hatch and then every second day to $20 \mathrm{~d}$ post-hatch. Three different feeding treatments were used: (1) algae (used as a control for behavior, to 
determine if motile prey elicited predation); (2) protozoans, Balanion sp.; (3) mixed protozoans, Balanion sp., and copepod nauplii Pseudodiaptomus sp. Prey densities were 15 to 30 cells $\mathrm{ml}^{-1}$ for protozoans and 1 nauplius $\mathrm{ml}^{-1}$ for copepod nauplii; these densities were selected because they were the same as those used in parallel studies (Hunt von Herbing \& Gallager 2000). Video-recording of foraging sequences were performed in three $10 \mathrm{l}$ glass aquaria (observation tanks) placed in a constant temperature water bath at $8.0 \pm$ $1^{\circ} \mathrm{C}$. All sequences involving Balanion sp. prey capture events were from the 'protozoans only' treatment (Treatment 2, above).

On the evening before each experiment, 50 to $60 \mathrm{cod}$ larvae were removed from the $100 \mathrm{l}$ rearing tanks and transferred to observation tanks. Each observation tank was covered with black plastic to exclude light, and the larvae were allowed to acclimate in the dark without food for $12 \mathrm{~h}$ until the following morning. Prior to filming, prey and about 11 of seawater were added to the observation tanks to produce homogenous distributions of prey. Estimates of local prey densities in each observation tank were determined by counting the number of prey in focus from video-recordings. Larval feeding and swimming behavior was recorded for $1 \mathrm{~h}$ between 09:00 and 12:00 h. After each experiment a subsample of 20 larvae was removed from each treatment to estimate total length. The effects of growth on prey selection by larval cod were examined by separating the larval cod into 3 size classes: Size Class $1=$ 5 to $6 \mathrm{~mm}$ ( 5 to $10 \mathrm{~d}$ post-hatch), Size Class $2=6$ to $7 \mathrm{~mm}$ (10 to $15 \mathrm{~d}$ post-hatch) and Size Class $3=7$ to $8 \mathrm{~mm}$ (15 to $20 \mathrm{~d}$ post-hatch).

The video-recording apparatus consisted of 2 orthogonal video cameras, providing views from the side (lateral) and from above (vertical) the filming vessel. The 51 observation tanks were illuminated laterally by a $40 \mathrm{~W}$ quartz halogen projector placed $10 \mathrm{~cm}$ from the tank. Neutral-density filters were used to regulate the intensity of light, which was approximately $10.0 \pm$ $1.0 \mu \mathrm{E} \mathrm{m} \mathrm{m}^{-2}$. This optical pathway resulted in dark-field images permitting resolution of objects as small as 30 to $50 \mu \mathrm{m}$ in the water column. The video-recording equipment included 2 Pulnix TM-7m video cameras with $100 \mathrm{~mm}$ macro-zoom lenses set at different magnifications. The vertical camera had a magnification that was $1.5 \times$ that of the horizontal camera. The differences in magnifications was taken into consideration when calibrating the view-field differences in magnification allowed for closer views of feeding events in the lateral plane and wider views in the vertical plane. The fields of view were calibrated by inserting a ruler into each tank prior to each experiment to determine length, width and depth of volume of view. The total volume for observation was $15 \mathrm{~cm}^{3}(3 \times 5 \times 1 \mathrm{~cm})$. The cameras were connected to a Panasonic NV-8500 VCR, and a Sony Trinitron 13 inch (ca $33 \mathrm{~cm}$ ) video monitor. Signals from both video cameras were passed through a frame-splitter to the VCR, resulting in 2 images, lateral $(X, Z)$ and vertical $(X, Y)$, produced simultaneously on one monitor screen. All foraging sequences were visible in 3-dimensions, and only sequences in focus were analyzed. The field of view was in the center of the aquarium and no data were collected from feeding events within $5 \mathrm{~cm}$ of the walls of the aquarium.

Feeding behavior - data analysis. Time codes were transferred to each video-recording using a time-code generator to determine the duration of each event during the foraging sequences. Using the image-analysis software OPTIMAS, positions of the prey, larval head, and larval tail were digitized frame-by-frame at an interval of $0.033 \mathrm{~s}$ throughout each foraging sequence. This produced a pair of coordinates $(X, Y$, from vertical; $X, Z$, from horizontal) for both the cod larvae and the prey item for each position. Three-dimensional displacements (distance, $\mathrm{cm}$ ), and swimming speeds (cm $\mathrm{s}^{-1}$ ), were calculated and plotted using the numerical analysis program MATLAB. The minimum estimate of larval swimming speed in the 3-dimensional behavioral studies was $0.01 \mathrm{~mm}^{-1}$.

Analysis of feeding was restricted to events during pursuit and attack, which included all behaviors after perception. Pursuit was defined as the interval from perception to attack (Fig. 1). Perception of the prey by
Fig. 1. Gadus morhua. Components of a pursuit and attack sequence by a cod larva feeding on a protozoan (Balanion sp.) or on a copepod nauplius (Pseudodiaptomus sp.); perception, pursuit, attack and capture

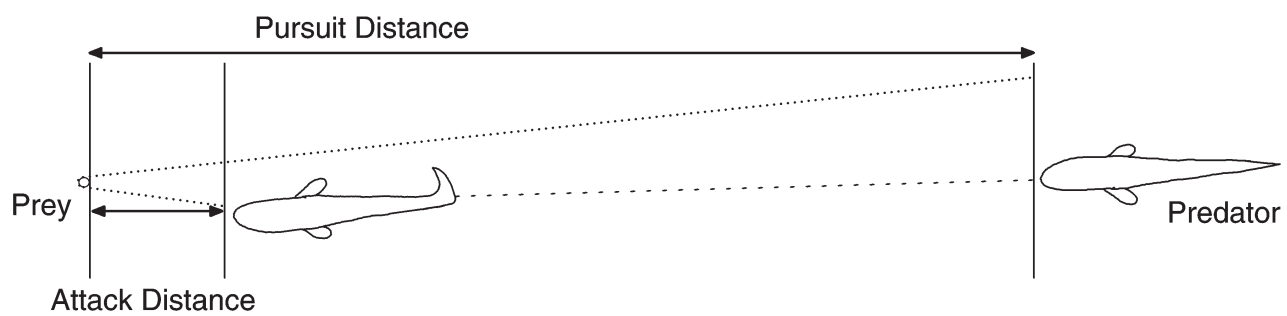

Capture Attack Perception

Pursuit 
a larva could be accurately determined by a sudden change in swimming direction and/or acceleration, followed by pursuit of prey. Perception distances were calculated from the distance between the position of the larva when it first perceived the prey and the position of the prey. Pursuit was composed of active swimming periods (bursts) and less active periods (glides) (see Hunt von Herbing \& Gallager 2000). From these, 6 specific variables were calculated: burst duration, distance and speed, and glide duration, distance and speed. Prior to attack, a larval cod would slow down and stop a short distance (attack distance) away from the prey, establishing a position for attack (Fig. 1). Three attack variables were calculated between attack location and capture: attack duration, distance, and speed. Changes in head and tail displacement and speed that characterize burst-and-glide swimming during pursuit and the rapid acceleration at attack were treated as separate variables in the calculation of larval cod swimming speed, and were factored into the calculations of specific energy expenditure and total energy expenditure.

Metabolic cost of swimming-experimental design. Specific metabolic rates during swimming were obtained from 37 respirometry experiments; these results were reported previously in Hunt von Herbing \& Boutilier (1996). Respirometry experiments were conducted at $10 \pm 1^{\circ} \mathrm{C}$. To estimate the energetics of swimming applicable to the present study, which involved larvae which ranged from 5 to $20 \mathrm{~d}$ post-hatch and were feeding externally, the yolk-larvae data included in Hunt von Herbing \& Boutilier's study were removed, and the regression coefficient was recalculated for feeding larvae only. Details of the respirometry apparatus, experimental procedure and analysis of activity patterns are given in Hunt von Herbing \& Boutilier (1996).

Metabolic costs of swimming — data analysis. Data from respirometry experiments (see Hunt von Herbing \& Boutilier 1996) provided estimates of mass-specific metabolic rates for time-averaged mean swimming speeds of larval cod ranging from 0.25 to $2.0 \mathrm{~mm} \mathrm{~s}^{-1}$. Mean swimming speeds and mean mass-specific metabolic rates varied synchronously over the first $35 \mathrm{~d}$ after hatching (Fig. 2).

The relationship between mass-specific oxygen uptake rates was positively correlated to swimming speed (Fig. 3). A first-order linear regression of the following form was found to be the best fit for the data:

$$
R(u)=a+b u ; \quad r_{\text {adj }}^{2}=0.61, \mathrm{p}<0.0005, \mathrm{n}=24
$$

where $R$ equals the specific metabolic rate and $u$ the swimming speed, $a$ is the standard metabolic rate at

zero swimming speed $\left(a=1.13 \mathrm{mg} \mathrm{O}_{2} \mathrm{~g}^{-1} \mathrm{~h}^{-1}\right)$, and $b$ the slope parameter $(b=8.94)$.

Two other functions, of the form, $R(u)=a+c u^{b}$ (power function, $\mathrm{r}^{2}$ adj $=0.59$ ) and $R(u)=a \mathrm{e}^{b u}$ (exponential function, $\mathrm{r}_{\text {adj }}^{2}=0.61$ ) were fitted, where $a$ is the standard metabolic rate and $b$ and $c$ are other parameters to be estimated. Extrapolations from these functions to zero swimming speed resulted in estimates of standard metabolic rates for the power relationship $a=3.12 \mathrm{mg} \mathrm{O}_{2} \mathrm{~g}^{-1} \mathrm{~h}^{-1}$, for the exponential relationship, $a=2.73 \mathrm{mg} \mathrm{O}_{2} \mathrm{~g}^{-1} \mathrm{~h}^{-1}$, and for the linear function $a=1.13 \mathrm{mg} \mathrm{O}_{2} \mathrm{~g}^{-1} \mathrm{~h}^{-1}$. Estimates of standard metabolic

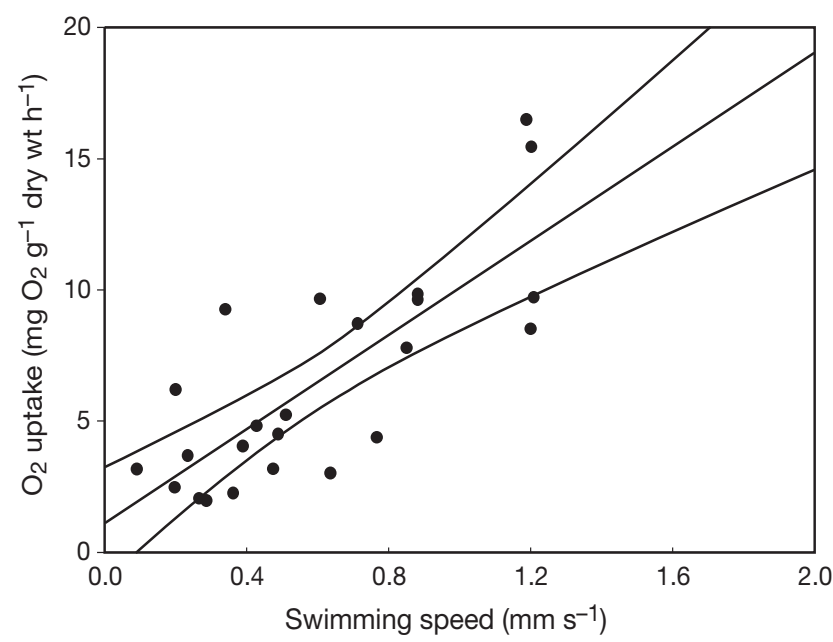

Fig. 3. Gadus morhua. Linear regression of mass-specific oxygen uptake versus swimming speed. Data points represent individual larvae, regression lines: means and $95 \% \mathrm{CI}$ 
rates from either the power function, exponential function or linear function were close to the recorded metabolic rates obtained from anaesthetized larval cod, which were 0.5 to $1.0 \mathrm{mg} \mathrm{O}_{2} \mathrm{~g}^{-1} \mathrm{~h}^{-1}$ (Davenport \& Lonning 1980). At higher swimming speeds, estimates of specific metabolic rates from the exponential model resulted in unrealistically high values (16-fold greater than the highest rates ever recorded for Atlantic cod larvae (Laurence 1978, Davenport \& Lonning 1980, Solberg \& Tilseth 1984, Hunt von Herbing \& White unpubl. data). Thus, the exponential model was eliminated from any further analysis. Estimates of specific metabolic rate from the power function at high swimming speeds resulted in more realistic values (only 1 order of magnitude higher than those predicted by the linear function). To determine which of these 2 models (i.e. the power or linear model) best fit the data, a sensitivity analysis (the PRESS criterion) was calculated. The PRESS (prediction sum of squares) criterion is a measure of how well the use of the fitted values for a subset model can predict the observed responses of $Y_{i}$ (i.e. specific metabolic rates) (Neter et al. 1996). Models with small PRESS values are considered good candidate models and have small prediction errors. The PRESS statistic for the power model was larger (PRESS $=192.5657)$ than the PRESS statistic for the linear model (PRESS =181.5721). Based on the PRESS statistic the linear model was chosen as the best model for the data.

To indicate the degree of uncertainty of the linear model, 95\% confidence intervals were calculated for the estimates of the slope for specific metabolic rates versus swim speeds for all 3 larval size classes. Predictions of metabolic rates for pursuit burst, pursuit glide, and attack swimming values were calculated. The predictions and standard errors were used to construct $95 \%$ confidence intervals (Student's critical value, $t[0.975, \mathrm{df}=23]=2.1)$. In this way, ranges of specific metabolic rates were obtained for pursuit, glide and attack components for all 3 larval size classes and provided levels of uncertainty in the linear model at the observed swimming speeds of prey pursuit. In the data set used to develop the equation, to estimate energy expenditure dry weights of larval fish ranged from 60 to $150 \mu \mathrm{g}$ and lengths from 5 to $8 \mathrm{~mm}$. Confidence intervals were also derived from the net energy gain equation to provide levels of uncertainty in the ranges of net energy gain for all larval size classes and the 2 prey types (see Table 2).

Metabolic costs of pursuit and attack and the net energy gain model. The net energy gained from the consumption of 1 prey item by a cod larva can be determined by using the net energy gain model. The net energy gain model used in the present study is a modification of traditional net energy gain models (e.g.
Emlen 1966, MacArthur \& Pianka 1966, Speakman 1986). The present model included pursuit burst speed, pursuit glide speed, and attack speed as separate variables to more closely approximate the swimming patterns during pursuit and attack of a prey item by a cod larva. The net energy gain (NEG) model is:

$$
N E G=\frac{E_{\mathrm{I}}-E_{\mathrm{E}}}{T_{\mathrm{t}}}
$$

where $E_{\mathrm{I}}$ equals total energy input, $E_{\mathrm{E}}$ total energy expenditures (i.e. $E_{\mathrm{E}}=E_{\mathrm{SE}}$, mean dry wt), and $T_{\mathrm{t}}$ the total time taken to acquire the number of prey eaten. Total mass-specific energy expenditures $\left(E_{\mathrm{SE}}\right)$ from perception to capture can be defined as the total massspecific metabolic cost spent in swimming during pursuit bursts and glides plus the total mass-specific metabolic cost spent swimming during attack (from attack location to capture; Fig. 1). $E_{\mathrm{SE}}$ was calculated for each size class as:

$$
E_{\mathrm{SE}}=\left(T B T \times \mathrm{e}_{\mathrm{b}}\right)+\left(T G T \times e_{\mathrm{g}}\right)+\left(T A T \times e_{\mathrm{a}}\right)
$$

where TBT equals total burst time, $e_{\mathrm{b}}$ estimated swimming mass-specific metabolism during pursuit bursts, TGT the total glide time, $e_{\mathrm{g}}$ the estimated standard mass-specific metabolism during pursuit glides, TAT the total attack time, and $e_{\mathrm{a}}$ the estimated swimming mass-specific metabolism during attack. When a cod larva swam actively, using its tail for propulsion, i.e. during pursuit bursts and during attack, the specific metabolic rates were estimated using Eq. (1) and swimming speeds during pursuit bursts attacks and mean dry mass for each larval size class. However, during glides when no active swimming occurred (the larva did not move forward by using its tail for propulsion), the mass-specific metabolic rate at zero swimming speed $\left(e_{\mathrm{g}}\right)$ was used to estimate specific metabolic rates during glides. Some assumptions of this model are: (1) that glide costs were based on estimates of standard metabolism (which may have underestimated the costs of this component since it was difficult to tell if the pectoral fins were moving even though the tail was not); (2) that specific dynamic action, SDA (or the cost of assimilation and digestion), did not affect the energy budget, (this assumption may not be true, but estimates of SDA for larval cod are presently unavailable to determine the proportion of aerobic scope taken up by SDA; larvae in both the behavioral and energetics experiments were not fed for $12 \mathrm{~h}$ prior to the experiments, so SDA from previous meals was not a factor); (3) that learning did not influence larvae, each strike being treated as a new occurrence. Furthermore, it should be noted that values of net energy gain and energy expenditure may be overestimates, since there was a $\pm 1{ }^{\circ} \mathrm{C}$ difference between the respirometry and observational studies. 
To determine the total energy expenditure during capture of a protozoan $\left(E_{\mathrm{I}}\right)$, the number of prey ingested (1 prey item per prey capture event) was multiplied by the estimated total energy content of one Balanion sp. The energy content of a Balanion sp. prey item was estimated to be $0.3 \mathrm{~mJ}$ (Finlay \& Uhlig 1981, Putt \& Stoecker 1989), and that of 1 copepod nauplius to be 7.0 mJ (Lasker 1962, Houde \& Schekter 1983).

\section{RESULTS}

\section{Patterns of pursuit and attack of protozoans and copepod nauplii by larval cod}

First-feeding Gadus morhua cod larvae readily pursued and captured protozoans (Balanion sp.), but did not capture copepod (Pseudodiaptomis sp.) nauplii. A pursuit, attack and capture sequence by a $5 \mathrm{~d}$ old cod larva on a protozoan is shown in Figs. $4 \mathrm{a}-\mathrm{c} \& 5 \mathrm{a}$, b. The larva approached the protozoan slowly. and the protozoan did not attempt to escape but continued to slowly swim (Fig. 5a,b). The larva slowed down at the attack distance, bent its tail into a J-posture, adjusted its position using its pectoral fins, and prepared to attack (Fig. 4b). Attack and capture occurred rapidly with a concomitant rapid extension of the tail and opening of the mouth as the larva moved toward the prey (Fig. 4c).

A pursuit, attack and a failed capture sequence of a $5 \mathrm{~d}$ old cod larva on a copepod nauplius is shown in Figs. $4 \mathrm{~d}-\mathrm{f} \& 5 \mathrm{c}, \mathrm{d}$. The larva swam in a series of rapid bursts and glides (Fig. 5c). It then slowed down and stopped, positioning itself and bending its tail into a J-posture for attack. Attack began at a greater distance from the nauplius (attack distance) than from the protozoan (Fig. 5c,d). The nauplius exhibited a few small low-velocity movements (jumps), but in general stayed stationary as the larva prepared for attack (Fig. 5c). As the larva began the attack, its tail extended and beat rapidly and its swimming velocity was high (Fig. 5c). The nauplius detected the larva and responded by jumping away and escaping at a velocity more than twice that of the attacking larva (Fig. 5c).

A total of 89 pursuits of protozoans by cod larvae were recorded. Of these, 61 pursuits and attacks were successful. Capture success increased with increasing larval size as follows: Size Class $1=62 \%$, Size Class $2=$ $68 \%$, Size Class $3=75 \%$. Increasing pursuit burst speed and decreasing burst duration led to faster and shorter pursuit sequences with increasing larval size (Table 1). However, larger larvae began pursuit at greater distances from the prey item than smaller larvae (Table 1). Similarly, larger larvae had significantly higher attack speeds than smaller larvae (Table 1).

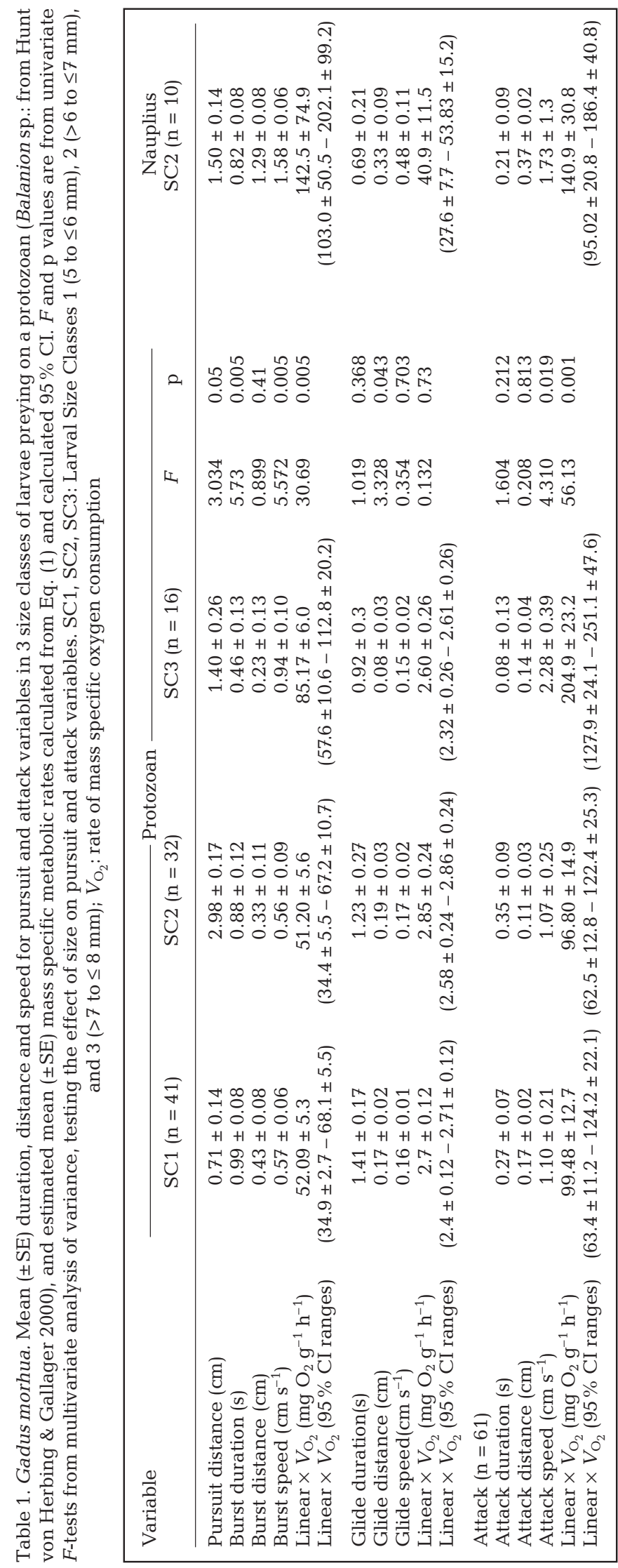


$\lambda$
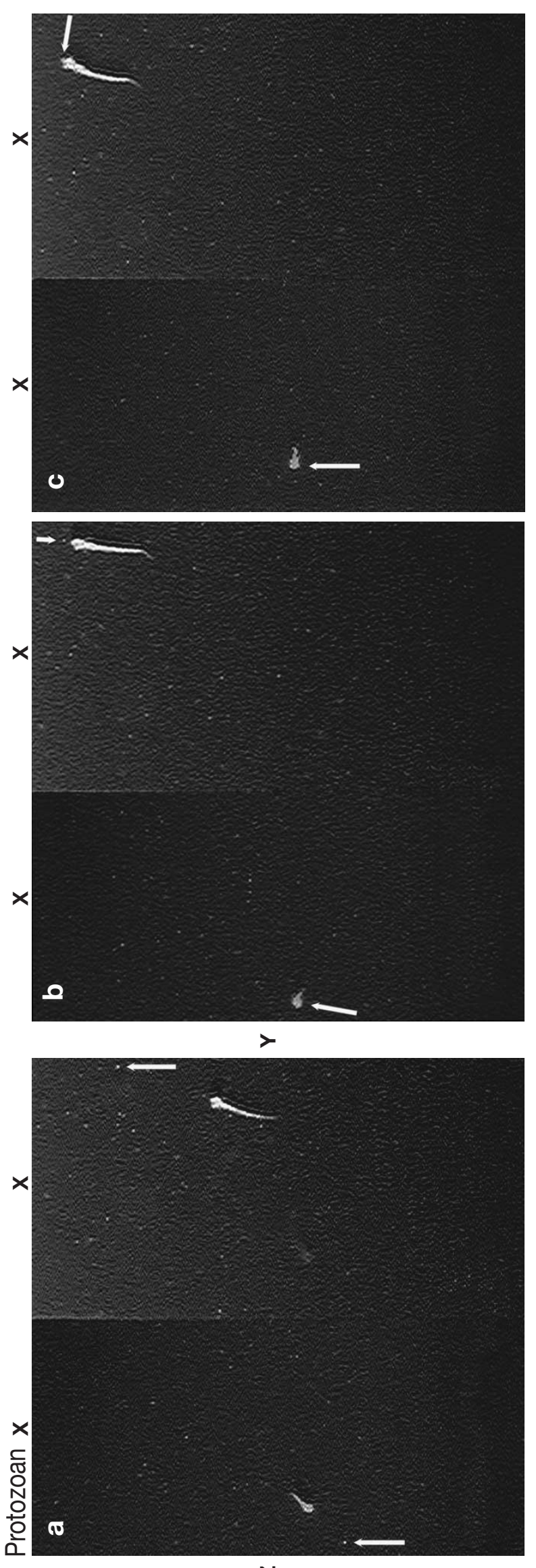

$\lambda$
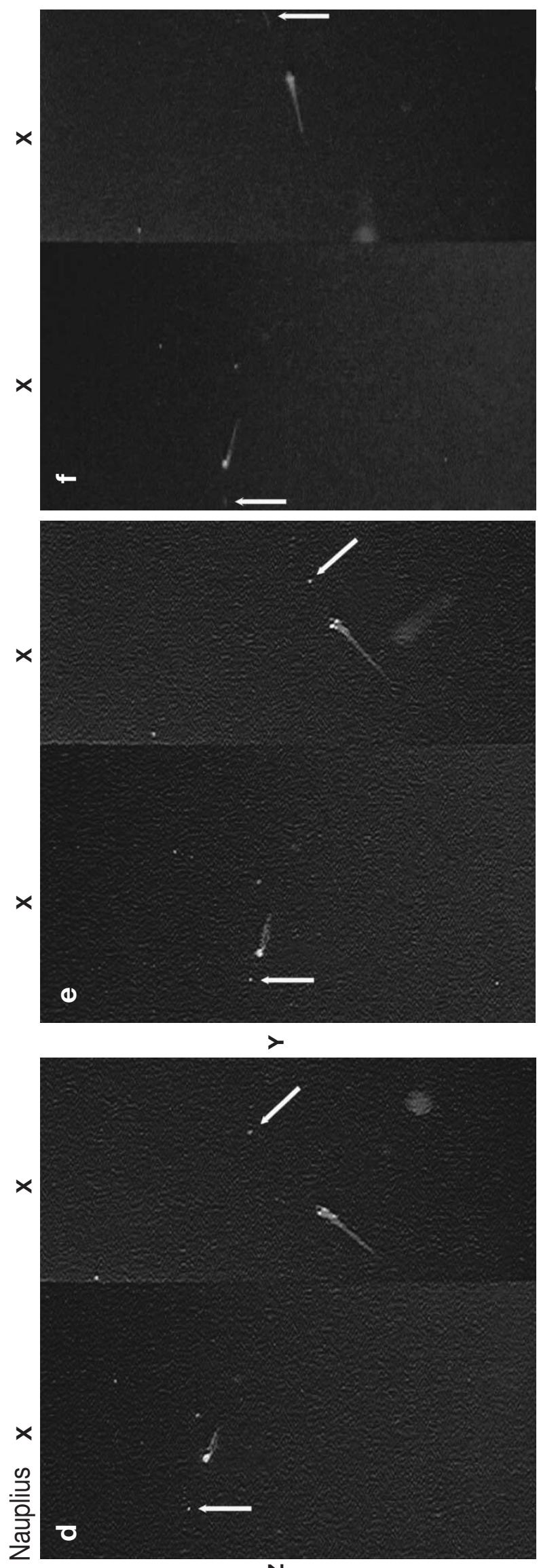


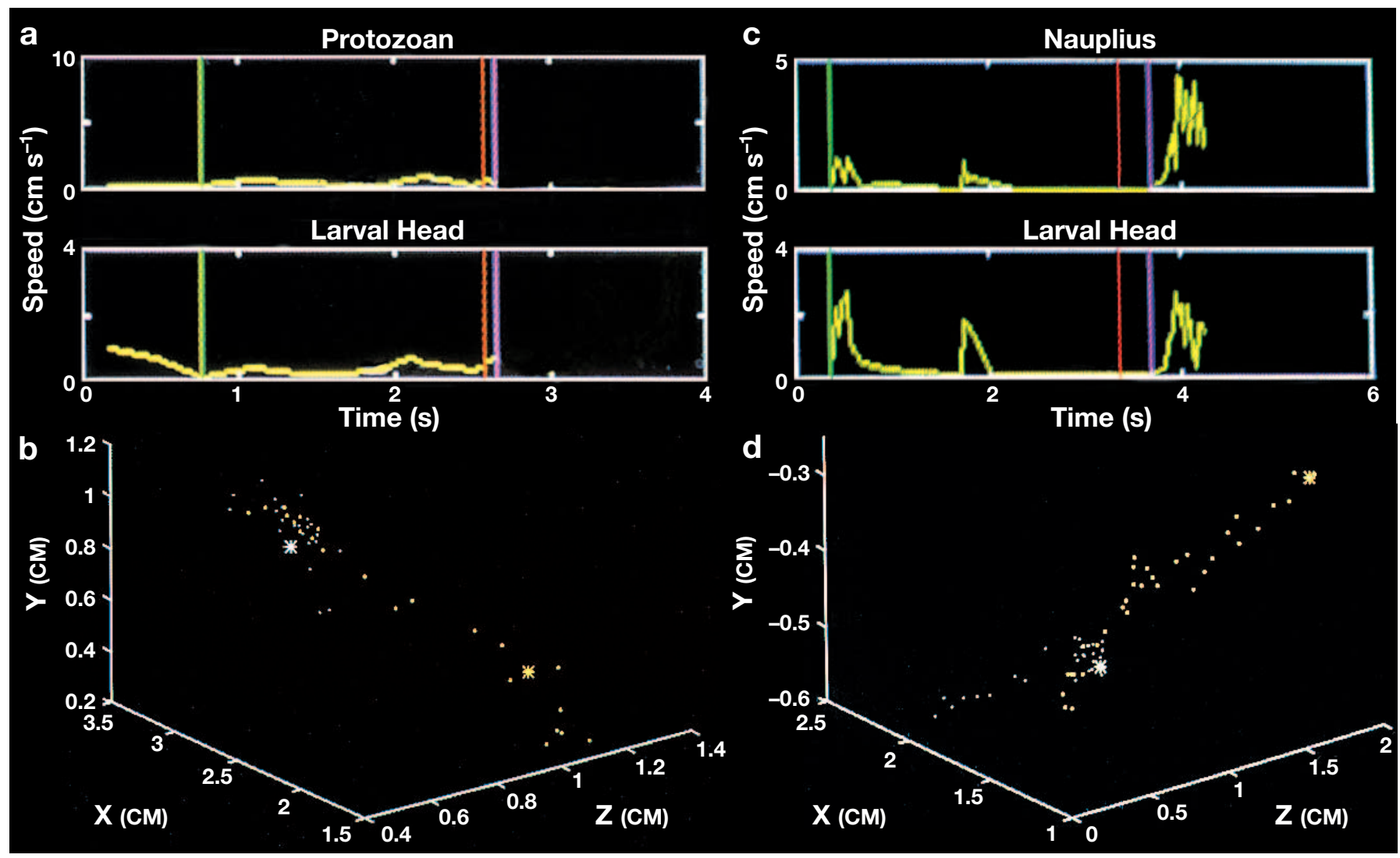

Fig. 5. Speed versus time of the head of a 5 d old Gadus morhua larva, a protozoan (Balanion sp., a, b) and a copepod nauplius (Pseudodiaptomus sp., c, d) and the corresponding frame-by-frame 3-dimensional representations during 1 pursuit, attack, and capture sequence, each. Event lines shown are perception (green), attack (red) and purple (capture). Yellow dots represent larval cod and white dots protozoan (b) or copepod nauplius (d). Yellow star: perception of the prey item by the larva, white star: successful capture of protozoan (b) and failed capture attempt for nauplius (d)

Glide duration and speed were not significantly different across larval size classes, although glide distance decreased with increasing larval size (Table 1). In the early stages of attack, cod larvae bent their tails into a J-posture at the attack distance prior to each capture event. However, with increasing larval size, the incidence of J-postures observed at the attack distance prior to capture decreased. In Size Class 3, cod larvae stopped at the attack distance for a very short time, attacked at high speeds (Table 1), and rarely exhibited a J-posture prior to capturing a protozoan.

A total of 20 pursuits of copepod nauplii by cod larvae were observed. Ten of these were by larvae belonging to the first size class and were unsuccessful. The first successful pursuits and attacks on copepod nauplii were by cod larvae of Size Class 2. The percentage of attacks on copepods (as a percentage of all attacks) increased from $19.6 \%$ in Size Class 1 to $23.0 \%$ in Size Class 2. Strikes on copepod nauplii occurred in Size Class 3, but were 2-dimensional (i.e. were in focus in only 1 camera view), and 3-dimensional distances and speeds could not be calculated. Comparisons of 3-dimensional larval cod pursuits and attacks on protozoans and copepod nauplii could only be made among cod larvae of Size Class 2.

The entire pursuit sequence by a cod larva in Size Class 2 of a nauplius occurred over a greater distance, but took less time than one on a protozoan (Table 1). Mean total pursuit of a nauplius by a larva was a factor of 1.5 times greater than for a protozoan (i.e. larvae perceived nauplii from greater distances than protozoans). Attack distances were also 3 times greater for a nauplius than for a protozoan (i.e. a larva did not have to get as close to a nauplius as to a protozoan prior to capture) (Table 1). Larval pursuit burst and attack speeds were 3 to 1.5 times faster respectively with nauplii than with protozoans (Table 1). Glide durations were shorter, distances longer and speeds faster during pursuit of nauplii than of protozoans (Table 1). 


\section{Specific metabolic rates of pursuit and attack}

For larval cod in pursuit of protozoans, mean estimated specific metabolic rates for pursuit and attack increased with increasing swimming speed, and larval size and mean specific metabolic rates were higher during attack than pursuit (Table 1). Mean estimated specific metabolic rates during attack were approximately double those of pursuit bursts across all size classes. Larval size affected specific metabolic rates, and were higher by a factor of 1.6 in Size Class 3 than in Size Class 1 for both pursuit burst and attack (Table 1). Glide speed did not vary with larval size, and estimated specific metabolic rates remained constant. Mean estimated specific metabolic rates during pursuit bursts and attacks increased 20 to 40 times over those of glides in all size classes (Table 1).

Overall mean predicted specific metabolic rates were lower for a larva preying upon a protozoan than on a nauplius (Table 1). During pursuit a protozoan, mean predicted specific metabolic rates for bursts were onethird lower than those during pursuit of a nauplius (Table 1). Similarly, mean predicted specific metabolic rates for attack of a protozoan were 1.3 times lower than for attack of a nauplius (Table 1). In addition, mean predicted specific metabolic rates for glides were also lower during pursuit of a protozoan than of a nauplius (Table 1).

Ranges of predicted specific metabolic rates, calculated from $95 \%$ confidence intervals, are also shown in Table 1. These ranges provided an estimate of the uncertainty in the linear model at the observed pursuit burst, pursuit glide and attack swimming speeds during pursuit of protozoans and nauplii by 3 size classes of larval cod.

\section{Energy expenditures and net energy gain}

Using Eq. (2), the parameters in Table 1 were used to calculate the total specific energy expenditure $\left(E_{\mathrm{SE}}\right)$ and the total energy expenditure $\left(E_{\mathrm{E}}\right)$ for larval cod pursuit and attack of both a protozoan and a nauplius.

During larval pursuit and attack of a protozoan, $E_{\mathrm{SE}}$ and $E_{\mathrm{E}}$ increased with increasing larval size (Table 2), but the total time for pursuit decreased (Table 2). Using the net energy gain model (Eq. 2), where input of energy $\left(E_{\mathrm{I}}\right)$ is the total energy content of the prey (1 protozoan or 1 nauplius), and total energy expenditure $\left(E_{E}\right)$ was calculated (see Table 2), a net gain in energy was revealed for all larval size classes (Table 2). Between Size Classes 1 and 3 there was a $19 \%$ increase in the net energy gained from the ingestion of a protozoan, with more than a doubling in mass and a $75 \%$ increase in total energy expenditure. The increase in the net energy gain with increasing larval size was due to $35 \%$ reduction in the pursuit time, which shortened the time over which energy was expended in pursuit (Table 2).

Successful capture by a larval cod of a copepod nauplius first took place in Size Class 2. The total specific energy expenditure $\left(E_{\mathrm{SE}}\right)$, and total energy expenditure $\left(E_{\mathrm{E}}\right)$, were 27 and $30 \%$ lower respectively for pursuit, attack and capture of a protozoan than of a nauplius (Table 2). While pursuit and attack by a larva of a protozoan required a smaller expenditure of energy than for a nauplius, the total time elapsed during pursuit and attack of a protozoan was $44 \%$ longer than that required for capture of a nauplius (Table 2). Therefore, the net energy gain was 2 orders of magnitude greater for capture of a nauplius than for a protozoan.

\section{DISCUSSION}

This study is the first to estimate the relative swimming costs during feeding of a marine fish larva, Atlantic cod Gadus morhua, on 2 planktonic prey organisms, a protozoan (Balanion sp.) and a copepod nauplius (Pseudodiaptomus sp.). Our results indicate that (1) specific metabolic rates and specific energy

Table 2. Gadus morhua. Estimates of energy expenditure and net energy gain (NEG) of larvae during pursuit and attack of a protozoan (Balanion sp.) and a copepod nauplius (Pseudodiaptomus sp.). Size Classes (SC) as in Table 1. Dry wt: mean dry weight $( \pm \mathrm{SE}), E_{\mathrm{I}}$ : total energy input from prey, $E_{\mathrm{E}}$ : total whole-body energy expenditure, $E_{\mathrm{SE}}$ : total specific energy expenditures; $T_{\mathrm{t}}$ : total time spent pursuing and attacking a prey item

\begin{tabular}{|lcccc|}
\hline Variable & \multicolumn{3}{c|}{ Protozoan } & Nauplius \\
\cline { 2 - 4 } & SC1 & SC2 2 & SC3 & 5.79 \\
\hline$T_{\mathrm{t}}(\mathrm{s})$ & 4.78 & 5.79 & 3.11 & $0.079 \pm 0.04$ \\
Dry wt $(\mathrm{mg})$ & $0.068 \pm 0.03$ & $0.079 \pm 0.04$ & $0.099 \pm 0.100$ & 7.0 \\
$E_{\mathrm{I}}(\mathrm{mJ})$ & 0.3 & 0.3 & 0.3 & $0.42(0.22-0.44)$ \\
$E_{\mathrm{SE}}(\mathrm{J} \mathrm{g}-1)(95 \% \mathrm{CI})$ & $0.46(0.31-0.6)$ & $0.45(0.30-0.59)$ & $0.70(0.51-1.00)$ \\
$E_{\mathrm{E}}(\mathrm{mJ})(95 \% \mathrm{CI})$ & $0.031(0.021-0.041)$ & $0.036(0.024-0.046)$ & $0.041(0.023-0.044)$ & $0.055(0.04-0.079)$ \\
NEG $(\mathrm{mW})(95 \% \mathrm{CI})$ & $0.056(0.054-0.058)$ & $0.045(0.043-0.048)$ & $0.083(0.082-0.089)$ & $2.68(2.67-2.69)$ \\
\hline
\end{tabular}


expenditure for pursuit components (both burst and glide) and attack increased with increasing larval size, (2) total energy expenditure during pursuit and attack increased with increasing larval size, and (3) net energy gain increased because total time (i.e. total time of pursuit + attack) decreased with increasing larvae size. Furthermore, results from the net energy gain equation indicated that (4) a cod larva gained 2 orders of magnitude more energy from a nauplius than from a protozoan, even though total larval energy expenditure, for the capture of a nauplius was 2 to 3 times that for a protozoan.

The model in the present study would seem to be an improvement upon previous models (e.g. Laurence 1977, Houde \& Schekter 1983) in estimating the metabolic costs of swimming during feeding, since each foraging component (e.g. pursuit burst, glide and attack) was included separately in the model. Previous models have only included average swimming speeds to estimate energy budgets (Laurence 1977, Houde \& Schekter 1983, Houde 1989, Werner et al. 1996) and describe foraging tactics (MacKenzie \& Kiørboe (1995). In those studies, metabolic rates were obtained from anesthetized larvae (Houde 1989) or from large numbers of larvae (10 to 20) swimming in small respirometer chambers (Houde \& Schekter 1983, Solberg \& Tilseth 1984), in which activity was neither monitored nor controlled (Laurence 1978). Activity levels were assumed to represent routine metabolic rates and were considered to be constant throughout the foraging cycle. Mackenzie \& Kiørboe (1995) used a combination of percent time spent swimming and mean swimming speeds to construct theoretical prey encounter models for 2 species of larval fish that differed in their foraging patterns, but did not go further to differentiate among foraging components (e.g. swimming speeds during pursuit vs attack). From the present study it is clear that different components of each foraging event require different expenditures of energy, e.g. swimming speeds during attack resulted in specific metabolic rates that were twice those in pursuit bursts. Since pursuit bursts were 3 times longer than attacks, the high specific metabolic rates were maintained for much shorter periods of time. The present energy expenditure model (Eq. 2) includes separate speeds and durations for each step in the foraging cycle and the number of components (e.g. number of bursts) per foraging event. In this way, the model presented in this study more closely describes the energy expended from perception to capture for each prey item than previous models, but is incomplete in that it does not include all steps of the foraging cycle and therefore would underestimate the true feeding costs.

The present model is open to criticism, particularly with respect to discrepancies between the velocities used in the respirometer studies and those observed in the behavioral study. MacKenzie \& Kiørboe (1995) dealt with such differences in a study of cod larvae feeding on Acartia tonsa. Instantaneous swimming velocities of 14 and $16 \mathrm{~mm} \mathrm{~s}^{-1}$ were recorded for $5.6 \mathrm{~mm}$ (small) and $6.1 \mathrm{~mm}$ (large) cod larvae (MacKenzie \& Kiørboe 1995). MacKenzie \& Kiørboe multiplied instantaneous swimming velocities by swimevent frequency $\left(0.41\right.$ events $\left.\mathrm{s}^{-1}\right)$ and swim duration $(0.3 \mathrm{~s})$ and found that time-averaged swim velocities (1.8 and $2.4 \mathrm{~mm} \mathrm{~s}^{-1}$ ) for small and large cod larvae were very close to time-averaged values actually observed by Solberg \& Tilseth (1984), Skiftesvik (1992) and recorded from a respirometry study (Hunt von Herbing \& Boutilier 1996). In the present study, our mean instantaneous pursuit speeds for each swimming event were 5.7,5.6, and $9.4 \mathrm{~mm} \mathrm{~s}^{-1}$ for larvae of 6 to $7 \mathrm{~mm}$ (SC1), 7 to $8 \mathrm{~mm}$ (Size Class 2) and 8 to $9 \mathrm{~mm}$ (Size Class 3). Multiplying instantaneous velocities for pursuit bursts by burst frequency (burst frequency = number of bursts [Table 1]/total event time [Table 2]) $(0.3,0.3,0.7 \mathrm{~s})$ and by burst duration $(0.99,0.88,0.46 \mathrm{~s})$, our time-averaged velocities $\left(2.1,1.5,3.1 \mathrm{~mm} \mathrm{~s}^{-1}\right)$ are also very close to those recorded by Solberg \& Tilseth (1984), Skiftesvik (1992), and MacKenzie \& Kiørboe (1995). More importantly, these values are very close to the time-averaged swimming speeds in the relationship between specific metabolic rates and swimming speed (Fig. 3) used to estimate energy expenditures in the present study. Thus, we can be fairly confident in using the relationship between specific metabolic rates and time-averaged swimming speeds to predict specific metabolic rates of pursuit, glide and attack components. In conjunction with event duration and event frequency (Table 1) we can also calculate energy expenditures (Eq. 1) and net energy gain (Eq. 2) for a cod larva feeding on a protozoan and/or a copepod nauplius.

Metabolic rates for swimming fish larvae are very difficult to estimate, since it is difficult to force fish larvae to swim at controlled speeds (Kauffman 1990). In studies of the swimming energetics of larval and juvenile fishes, relationships between specific metabolic rates and swimming speed have been described by an exponential function in salmon fry (Ivlev 1960a,b), and larval coregonids (Dabrowski et al. 1986), and by a power function in the roach Rutilits rutilus (Kauffman 1990). Although exponential and power functions were fit to our metabolic and swimming speed data for cod larvae (Hunt von Herbing \& Boutilier (1996), a linear relationship proved to be the best fit. This relationship fitted the data over the slower swimming speeds of the larvae within the respirometer chamber, but may have underestimated the metabolic rates at higher speeds (i.e. during prey pursuit and attack), since metabolic 
rates level off at the highest speeds in juvenile and adult fishes, when anaerobic processes and the concomitant oxygen debt begin to contribute to total metabolism (Brett 1964, Kauffman 1990). However, anaerobic processes are thought to constitute but a very small fraction of the total metabolism of larval fishes (Rombough 1988, Wieser \& Kauffman 1998), and therefore a linear relationship between oxygen uptake and swimming speeds may be appropriate.

Both the exponential function used for salmon (Ivlev $1960 \mathrm{a}, \mathrm{b})$ and the power function used for roach larvae (Kauffman 1990), may be applicable to larger larval fish which swim at faster speeds and inhabit inertial envionments (i.e. Reynolds number >300: Fuiman \& Batty 1997). Both salmonid and roach larvae are an order magnitude larger than cod larvae at hatching (5 mg dry wt) for Salmo salar, $1.4 \mathrm{mg}$ wet wt for Rutilus rutihis vs $0.06 \mathrm{mg}$ dry wt for Gadus morhua). A rough calculation suggests that cod larvae swim mostly in viscous environments (i.e. $\mathrm{Re}<10$ for glide speeds, 20 to 40 for burst speeds and 50 to 100 for attack speeds). However, since cod larvae do not swim continuously (continuous swimming is necessary to calculate Re number accurately: L. Fuiman pers. comm.), but in a burst and glide pattern, estimates of Re number are crude at best. It may be that the hydrodynamic principles that necessitate the use of power-performance relationships in inertial regimes such as those inhabited by the larger salmon, roach and bleak larvae may be different at low Re number regimes. The linear relationship between specific oxygen uptake and swimming speed used in the present study may be the best to date for very small fish larvae swimming in viscous regimes.

A further criticism of the present study is that we only estimated the cost of pursuit and attack and did not estimate search costs. In many studies search costs, which determine encounter rates, are considered to be one of the most important aspects of larval fish-feeding energetics (O'Brien et al. 1989, Browman \& O'Brien 1992a,b, Mackenzie \& Kiørboe 1995). While this may be so, search costs are extremely difficult to estimate for larval fish. For golden shiner larvae, which are saltatory searchers, the amount of time spent in searching, which included swimming moves to new search space, increased with increasing larval size (mean swimming speed increased from 13.5 to $27.5 \mathrm{~mm}$ $\mathrm{s}^{-1}$ ) and represented at least $50 \%$ of the total foraging time (Browman \& O'Brien 1992a,b). This suggests that if search costs were included in the foraging models, total energy expenditures would be even higher and energy gain lower per ingested of prey item than calculated in the present study.

First-feeding cod larvae (Size Class 1) may be constrained by morphology, whereas older larger cod lar- vae (Size Classes 2 and 3) may be limited by metabolic demands for prey capture. For first-feeding larval cod, protozoans provided sufficient net energy gain to offset the energy expenditure during pursuit and capture. Larval cod include copepod nauplii in their diet when the larvae are larger and have better developed feeding structures and mechanisms which provide greater capture ability and can generate faster swimming speeds in the pursuit of faster and larger prey (Hunt von Herbing \& Gallager 2000). Although, in our study, increases in swimming speed necessitated increased energy expenditure, the specific energy expenditure per feeding event decreased. This decrease in metabolic cost was due to shorter total pursuit and attack durations, so that although larval cod were swimming faster they were also swimming for a shorter time and over a shorter distance. This resulted in a decrease in the total metabolic cost for each feeding event with increasing in larval size. These results suggest that changes in foraging parameters throughout the various larval stages may affect energy balances and thus growth and mortality rates during the early life history of cod larvae.

Acknowledgements. We wish to thank Phil Alatalo and Linda Davis for their invaluable help in every aspect of the project using 3-D video. We would also like to thank Lucy Blanchard for her assistance in extracting data from video and Peter Brickley for his help with MATLAB. All experimental work using 3-1 video was carried out at the Environmental Systems Laboratory at Woods Hole Oceanographic Institution, Woods Hole, Massachusetts, USA. All respirometry experiments were carried out Dalhousie University, Halifax, Nova Scotia, Canada. All analysis, model formulation, and manuscript preparation was conducted at the University of Maine, Orono. This work was supported by a grant from the National Science Foundation to SMG (90CE 9313680) and a MAFES grant to $\mathrm{IHvH}(2477)$.

\section{LITERATURE CITED}

Brett JR (1964) The respiratory metabolism and swimming performance of young sockeye salmon. J Fish Res Board Can 21:1183-1226

Brett JR, Groves TDD (1979) Physiological energetics. In: Randall WS, Randall DJ, Brett JR (eds) Fish physiology. Academic Press, New York, p 279-352

Browman HI, O'Brien WJ (1992a) The ontogeny of search behavior in the white crappie, Pomoxis annularis. Environ Biol Fish 34:181-195

Browman HI, O'Brien WJ (1992b) Foraging and prey search behavior of golden shiner (Notemigonus crysoleucas) larvae. Can J Fish Aquat Sci 4:813-819

Buskey EJ, Coulter C, Strom S (1993) Locomotory patterns of microzooplankton: potential effects on food selectivity of larval fish. Bull Mar Sci 53:29-43

Coughlin DJ, Strickler JR, Sanderson B (1992) Swimming and search behavior in clownfish, Amphiprion perideraion, larvae. Anim Behav 44:427-440

Dabrowski KR, Kok LY, Takashima F (1986) How efficiently 
do fish larvae and juveniles swim? Comp Biochem Physiol 85A:657-661

Davenport J, Lonning S (1980) Oxygen uptake in developing eggs and larvae of the cod, Gadus morhua L. J Fish Biol 16:249-256

Emlen JM (1966) The role of time and energy in food preference. Am Nat 100:611-617

Finlay BJ, Uhlig G (1981) Calorific and carbon values of marine and freshwater protozoa. Helgol Meeresunters 34:401-412

Fuiman LA, Batty RS (1997) What a drag it is getting cold: partitioning the physical and physiological effects of temperature on fish swimming. J Exp Biol 200:1745-1755

Gallager SM, von Herbing I, Davis L, Alatalo P (1996) Yolksac cod larvae ingest microzooplankton exclusively from natural plankton assemblages on Georges Bank. In: Proceedings of the Ocean Sciences Meeting, Feb 12-16, 1996, San Diego, CA, p 1032

Houde ED (1989) Comparative growth, mortality, and energetics of marine fish larvae: temperature and implied latitudinal effects. Fish Bull 87:471-495

Houde ED, Schekter RC (1983) Oxygen uptake and comparative energetics among eggs and larvae of three subtropical marine fishes. Mar Biol 72:283-293

Hunt von Herbing I, Boutilier RG (1996) Activity and metabolism of larval Atlantic cod (Gadus morhua) from Scotian Shelf and Newfoundland source populations. Mar Biol 124: $607-618$

Hunt von Herbing I, Gallager SM (2000) Foraging behavior in early Atlantic cod larvae (Gadus morhua) feeding on a protozoan (Balanion sp.) and a copepod nauplius (Pseudodiaptomus sp.). Mar Biol 136:591-602

Hunter JR (1981) Feeding ecology and predation of marine fish larvae. In: Lasker (ed) Marine fish larvae, morphology, ecology and relation of fisheries. Washington Sea Grant Program. University of Washington Press, Seattle, p 34-87

Ivlev VS (1960a) 'Active metabolic intensity in salmon fry (Salmo salar L.) at various rates of activity'. Pap No 213 (mimeo) Salmon and Trout Comm International Council for the Exploration of the Sea, Copenhagen

Ivlev VS (1960b) On the utilization of food by planktophage fishes. Bull Math Biophys 22:371-389

Kauffman R (1990) Respiratory cost of swimming in larval and juvenile cyprinids. J Exp Biol 150:343-366

Kiørboe T, Visser AW (1999) Predator and prey perception in copepods due to hydromechanical signals. Mar Ecol Prog Ser 179:81-95

Lasker R (1962) Efficiency and rate of yolk utilization by developing embryos and larvae of the Pacific sardine (Sardinops caerulea). J Fish Res Board Can 19:867-875

Laurence GC (1977) A bioenergetic model for the analysis of feeding and survival potential of winter flounder, Pseudopleuronectes americanus, larvae during the period from hatching to metamorphosis. Fish Bull 75:529-546

Laurence GC (1978) Comparative growth, respiration and delayed feeding abilities of larval cod (Gadus morhua) and haddock (Melanogrammus aeglefinus) as influenced

Editorial responsibility: Howard Browman (Contributing Editor), Storebø, Norway by temperature during laboratory studies. Mar Biol 50:1-7 MacArthur RH, Pianka ER (1966) On the optimal use of a patchy environment. Am Nat 100:603-609

MacKenzie BF, Kiørboe T (1995) Encounter rates and swimming behavior of pause travel and cruise larval predators in calm and turbulent environments. Limnol Oceanogr 40: 1278-1289

Neter J, Kutner MH, Nachtscheim CJ, Wasserman W (1996) Applied linear statistical models, 4th edn. Richard D. Irwin, Chicago

O'Brien WJ, Evans BI, Browman HI (1989) Flexible search tactics and efficient foraging in saltatory searching animals. Oecologia 80:100-110

Putt M, Stoecker DK (1989) An experimentally determined carbon:volume ratio for marine 'oligotrichous' ciliates from estuarine and coastal waters. Limnol Oceanogr 34: $1097-1103$

Rombough PJ (1998) Respiratory gas exchange, aerobic metabolism and effects of hypoxia during early life. In: Hoar WS, Randall DJ, Brett JR (eds) Fish Physiology, Vol IIa:57-159, Academic Press, New York

Skiftesvik AB (1992) Changes in behavior at onset of exogenous feeding in marine fish larvae. Can J Fish Aquat Sci 49:1570-1572

Solberg T, Tilseth S (1984) Growth, energy consumption and prey density requirements in first feeding larvae of cod (Gadus morhua). In: Dahl E, Danielsen DS, Moksness E, Solemdal P (eds) The propagation of cod (Gadus morhua). Flødevigen Rapp No. 1. Arendal, Norway, p 145-166

Speakman JR (1986) The optimum search speed of terrestrial predators when feeding on sedentary prey: a predictive model. J Theor Biol 122:401-407

Stoecker D, Guillard RRL, Kavee RM (1981) Selective predation by Favella ehrenhergii (Tintinnina) on and among dinoflagellates. Biol Bull 160:136-145

Strickler JR (1975) Intra- and interspecific information flow among planktonic copepods receptors. Verh Int Verein Limnol 19:2951-2958

Strickler JR, Bal AK (1973) Setae of the first attennae of the copepod Cyclos scutifer (Sars): their structure and importance. Proc Natl Acad Sci USA 70:2656-2659

Viitasalo M, Kiørboe T, Flinkman J, Pedersen LW, Visser AW (1998) Predation vulnerability of planktonic copepods: consequences of predator foraging strategies and prey sensory abilities. Mar Ecol Prog Ser 175:129-142

Vlymen WJ 111 (1974) Swimming energetics of the larval anchovy (Engraulis mordax). Fish Bull 72:885-899

Ware DM (1975) Growth, metabolism and optimal swimming speed of a pelagic fish. J Fish Res Board Can 32:33-41

Werner FE, Perry RI, Lough RG, Naimie CE (1996) Trophodynamic and advective influences on Georges Bank larval cod and haddock. Deep-Sea Res Part II Top Stud Oceanogr 43:1793-1822

Wieser W, Kauffman R (1998) A note on interactions between temperature, viscosity, body size and swimming energetics in fish larvae. J Exp Biol 201:1369-1372

Submitted: January 6, 2000; Accepted: October 27, 2000 Proofs received from author(s): June 11, 2001 